\title{
Análise dos projetos de desenvolvimento dos vales dos rios Tietê e Paraná*
}

\author{
Elaine Mendonça Bernardes** \\ Fernando Curi Peres***
}

S U MÁR IO: 1. Introdução; 2. Metodologia; 3. Conclusão.

S UMMARY : 1. Introduction; 2. Method; 3. Conclusion.

P ALA VRA S - CHA VE: análise de projetos; método da estrutura lógica; desenvolvimento regional; hidrovia Tietê-Paraná; planos de desenvolvimento.

KEY WORDS: project analysis; logical structure method; regional development; Tietê-Paraná waterway; development plans.

Este artigo avalia as alternativas propostas para a região dos vales dos rios Tietê e Paraná, no estado de São Paulo. Os projetos formalmente elaborados para a região foram analisados através do método da estrutura lógica. Tal método consiste em representar um projeto na forma de uma matriz $4 \times 4$ cujos elementos permitem a análise do projeto em questão pela utilização de critérios relacionados ao método científico, à análise de sistemas e ao ponto de vista da gerência de programas. Os resultados encontrados demonstraram a inconsistência nos planos e projetos existentes para a região.

Analyzing the development projects for the Tietê and Paraná valleys

\footnotetext{
* Artigo recebido em ago. 2004 e aceito em set. 2005.

** Professora doutora do Departamento de Fitotecnia, Tecnologia de Alimentos e Socioeconomia da FE/ Unesp. Doutora em economia aplicada pela Esalq/USP, engenheira agrônoma, M.S. Endereço: Av. Brasil Centro, 56 - Caixa Postal 31 - CEP 15385-000, Ilha Solteira, SP, Brasil. E-mail: emb@agr.feis.unesp.br.

*** Professor titular do Departamento de Economia e Sociologia Rural da Esalq/USP. PhD em economia pela Ohio State University, engenheiro agrônomo, M.S. pela Universidade Federal de Viçosa. Endereço: Av. Pádua Dias, 11 - São Dimas - Caixa Postal 9 - CEP 13418-900, Piracicaba, SP, Brasil. E-mail: fcperes@carpa.ciagri.usp.br.
} 
This article analyzes the proposed alternatives expressed in the plans and projects for the region of the Tietê and Paraná valleys, in the state of São Paulo, Brazil. The plans and projects were analyzed by the logical structure method, which consists in representing a project in a $4 \times 4$ matrix. The elements of the matrix make it possible to analyze the project using criteria related to the scientific method, systems analysis and program management. The results revealed inconsistencies in the existing plans and projects for the region.

\section{Introdução}

A região dos vales dos rios Tietê e Paraná manteve-se à margem do processo de desenvolvimento, apesar dos investimentos realizados nas últimas décadas. As obras relacionadas à geração de energia e navegabilidade dos rios foram realizadas pela Companhia Energética de São Paulo (Cesp). Elas incluíram até mesmo a construção de cidades, o que estava perfeitamente de acordo com a visão predominante, naquela época, do Estado enquanto “construtor” de obras como determinantes do desenvolvimento. A Cesp desempenhou seu papel dentro de uma visão das possibilidades de desenvolvimento provavelmente influenciada pela teoria dos pólos. Isso pode ser observado, por exemplo, em trechos nos quais a empresa se refere aos pólos regionais de turismo que constituiriam pontos estratégicos a serem operados de forma integrada. O contexto em que a Cesp foi fundada, no qual prevalecia a teoria dos pólos, parece ter influenciado a visão dessa empresa sobre o desenvolvimento regional.

As tentativas de planejar o aproveitamento das obras nos rios Tietê e Paraná, para o desenvolvimento, sob uma ótica regional, iniciaram-se no governo Montoro (período 1983-86) e, desde então, três planos governamentais foram elaborados mas não efetivamente implantados. Além deles, o setor privado esboçou um plano para atrair investimentos para a região, mas o interesse foi menor que o esperado. A Agência de Desenvolvimento do Tietê-Paraná (ADTP) — responsável pelo Master Plan - embora tenha mantido este nome, direcionou seus trabalhos para projetos de infra-estrutura em outras partes do país. Além desses três planos de caráter regional, alguns outros projetos para municípios específicos da região também não surtiram, até o momento, os efeitos esperados. É de se supor que tais planos e projetos tenham traços em comum que gerem a frustração das expectativas. Este artigo avalia criteriosamente as possíveis razões para a frustração das expectativas contidas nos planos que não alcançaram os resultados esperados, uma vez que foram envolvidos recursos públicos.

\section{Metodologia}


Os projetos formalmente elaborados para a região dos vales dos rios Tietê e Paraná foram analisados pelo método da estrutura lógica, desenvolvido pela Practical Concepts Inc. (Management Systems International) e apresentado na Norwegian Agency for Development Co-operation (Norad, 1999), que consiste em representar um projeto na forma de uma matriz $4 \times 4$, cujos elementos permitem a análise do projeto em questão através da utilização de critérios relacionados à análise de sistemas e à responsabilidade gerencial do programa e ao método científico. O método da estrutura lógica pode ser usado para planejamento, elaboração do projeto em si, implementação e avaliação de projetos. Ele fornece uma estrutura para estabelecer prioridades e determinar resultados e atividades pretendidos pelo projeto. Pode ainda fortalecer as bases para que se avalie a sua efetividade, eficiência e relevância (Jackson, 1998).

A necessidade de definir um sistema maior no qual o projeto esteja inserido é uma exigência da análise de sistemas. A metodologia da estrutura lógica (o ponto de vista do gerenciamento) estabelece que, se o objetivo do gerenciamento é atingir determinados resultados, espera-se que os gerentes sejam responsáveis por eles. Tal responsabilidade diz respeito a três níveis hierárquicos básicos, chamados de insumos, produtos e propósito. Os insumos são consumidos para gerar os produtos (os resultados a serem atingidos pelos gerentes) e possibilitam atingir o nível seguinte (o propósito, a razão de ser do projeto).

A colaboração do método científico na estrutura lógica consiste no tratamento claro da incerteza na elaboração do projeto. As informações contidas no projeto devem mostrar as incertezas envolvidas pela explicitação dos pressupostos incorporados na análise. A utilização da estrutura lógica possibilita que a relação "se A então B” seja verificada. Por exemplo, nos níveis mais baixos de objetivos (onde estão os insumos e produtos do projeto) pode-se ler a proposição: se os insumos são executados e os correspondentes pressupostos são verificados, então os produtos devem acontecer. No segundo nível pode-se ler: se produtos e pressupostos, então os propósitos. No nível mais elevado da hierarquia gerencial (acima do propósito do projeto), a mesma relação indica que se os propósitos são alcançados e os pressupostos verificados, então o fim deve ser alcançado (o último nível da hierarquia que significa a especificação completa do sistema ao preencher a exigência da análise de sistemas).

De acordo com Jackson (1998), na realidade, há vários métodos de estrutura lógica, mas há um método genérico que pode ser adaptado às necessidades do usuário ou da agência financiadora do projeto. Usualmente, a estrutura lógica consiste, segundo ele, em uma fase de análise e de planejamento com três passos cada fase, conforme o quadro 1 . O autor define sucintamente cada um dos passos apresentados no quadro $1 \mathrm{e}$ apresenta os pontos fracos e os requisitos para se desenvolver uma estrutura lógica. Aqui, analisam-se projetos já existentes e não se elabora um novo projeto. Assim, detalhar os primeiros passos do quadro 1 - análise dos problemas - não se faz 
necessário. Entretanto, é importante para o entendimento do método que se observe que, quando desenvolvido de acordo com os passos do quadro 1, um projeto preenche, quase automaticamente, a matriz de estrutura lógica indicada no quadro 2. A matriz seria elaborada a partir da análise estratégica (último passo da fase de análise) e assim daria início à fase de planejamento do projeto.

\section{Quadro 1}

Fases do método da estrutura lógica

\begin{tabular}{ll}
\hline Fase de análise & Fase de planejamento \\
\hline Análise dos problemas & Estrutura lógica \\
Análise de objetivos & Cronograma de atividades \\
Análise de estratégias & Insumos e cronograma de custos
\end{tabular}

Fonte: Jackson, 1998.

Se um projeto for desenvolvido segundo a estrutura lógica, os objetivos, propósitos, produtos e atividades serão transcritos da “árvore de estratégia” produzida na análise de estratégias (último passo da fase de análise) para as colunas e linhas da matriz da estrutura lógica. A finalidade de se especificar os pressupostos é identificar fatores externos que afetarão o sucesso do projeto. Uma vez identificados os pressupostos, de acordo com Itad (1996), segundo Jackson (1998), eles são estabelecidos em termos da situação desejada. Em outras palavras, o projeto estabelece que, uma vez atingido um nível hierárquico e ocorrendo a situação desejada (o pressuposto), outro nível do projeto é alcançado.

Sobre os indicadores e seus respectivos meios de verificação, Jackson (1998) apresenta algumas características desejadas. Cada indicador deve ser objetivamente verificável e estabelecido segundo alguns critérios: deve ser mensurável; deve ser exeqüível (em termos financeiros, de equipamentos, estratégias e tempo); deve ser relevante e preciso (ou seja, deve refletir o que se está tentando medir de modo acurado); deve ser sensível (o que significa ser capaz de captar mudanças ao longo do período de tempo em questão); e deve ser capaz de fornecer informação em tempo hábil. Uma vez estabelecidos os indicadores, as fontes de informação e os meios de coleta devem ser estabelecidos. O meio de verificação deve testar se o indicador ao qual está associado pode ou não ser realisticamente mensurado dentro de limites razoáveis de tempo, dinheiro e esforço. Cada meio de verificação deve especificar o formato no 
qual a informação estará disponível, quem a fornecerá e com que regularidade esta será fornecida (Itad, 1996, conforme Jackson, 1998).

\begin{tabular}{|c|c|c|c|}
\hline & A matriz da e & o 2 & \\
\hline Objetivos/atividades & Indicadores objetivos & Meios de verificação & Pressupostos \\
\hline $\begin{array}{l}\text { Objetivos globais } \\
\text { ou fim }\end{array}$ & $n$ indicadores & $\begin{array}{l}\text { Meios de verificação } \\
\text { dos } n \text { indicadores }\end{array}$ & \\
\hline $\begin{array}{l}\text { Propósito do } \\
\text { projeto }\end{array}$ & $x$ indicadores & $\begin{array}{l}\text { Meios de verificação } \\
\text { dos } x \text { indicadores }\end{array}$ & Pressupostos \\
\hline $\begin{array}{l}\text { Resultados ou } \\
\text { produtos }\end{array}$ & $y$ indicadores & $\begin{array}{l}\text { Meios de verificação } \\
\text { dos } y \text { indicadores }\end{array}$ & Pressupostos \\
\hline $\begin{array}{l}\text { Atividades ou } \\
\text { insumos }\end{array}$ & $z$ indicadores & $\begin{array}{l}\text { Meios de verificação } \\
\text { dos } z \text { indicadores }\end{array}$ & Pressupostos \\
\hline
\end{tabular}

A estrutura lógica é um instrumento poderoso para análise de projeto (Itad, 1996, segundo Jackson 1998). O mesmo autor apresenta uma seqüência para avaliação de projetos por esse método. Nela, as inconsistências da elaboração do projeto são verificadas em: problemas não endereçados pelos objetivos; objetivos para os quais nenhum problema correspondente foi identificado; e diferenças em relações entre causa-efeito/meios-fins e entre a “árvore problema” e a “árvore objetivo”. A estrutura lógica pode, de acordo com Jackson (1998), ser utilizada também para projetos que não tenham sido elaborados utilizando-se de tal estrutura. Nesse caso, a fase de análise deve ser encurtada, usando-se os objetivos do projeto e desenvolvendo-se uma matriz de estrutura lógica. Esse será o procedimento adotado neste artigo, considerando-se que se sabe, de antemão, que a estrutura lógica não foi utilizada na elaboração dos projetos.

\section{Resultados e discussões}

A análise do Projeto Calha permitiu o preenchimento apenas da coluna que o resume (as suas intenções) e a dedução de indicadores objetivos e meios de verificação correspondentes, nos dois níveis hierárquicos inferiores da matriz de estrutura lógica. Na realidade, o texto analisado não foi o projeto em si (que não foi encontrado), mas sim a "síntese do relatório técnico entregue em dezembro de 1993” (CITP, 
1994, página de apresentação), ou seja, um documento sobre o cumprimento da primeira fase do projeto. A partir desse documento, elaborou-se o quadro 3.

De CITP (1994), é possível deduzir que o Projeto Calha propôs inicialmente que as informações caracterizadoras das sub-regiões que o compunham fossem devidamente utilizadas para se estabelecerem as diretrizes específicas para cada subregião. Dessa forma, entendeu-se que essas informações foram os insumos. As diretrizes específicas para cada sub-região lindeira foram o produto gerado a partir dos insumos. Uma vez estabelecidas as diretrizes, o propósito do projeto, ou a sua razão de ser, seria o surgimento de um novo modelo de gestão que operacionalizasse as diretrizes do plano. Esse é o encadeamento lógico resumido na primeira coluna do quadro 3.

O método da estrutura lógica estabelece que os pressupostos do projeto devem ser explicitados, o que não ocorreu no Projeto Calha, em nenhum nível hierárquico, conforme o quadro 3. Isso implica que a elaboração do projeto não obedeceu ao requisito do método científico, ou seja, não introduziu a incerteza.

No nível hierárquico mais baixo no Projeto Calha, um pressuposto importante seria, por exemplo, que as informações coletadas estivessem adequadas e fossem suficientes para estipular as diretrizes. No nível hierárquico imediatamente superior, implicitamente, o texto pressupõe a continuidade dos estudos. Sabe-se que não houve essa continuidade. Além disso, no mesmo nível pressupôs-se que houvesse interesse em um novo modelo de gestão. Esse aspecto pode ter sido relativamente importante para a interrupção dos estudos. Afinal, o risco associado a uma redefinição das regiões administrativas do estado de São Paulo pode não ter sido interessante (do ponto de vista político) e colaborado para "minar" a continuidade dos estudos pelos órgãos envolvidos, além de desestimular a implantação das diretrizes estabelecidas no plano.

Para que o modelo de gestão que seria proposto pelo projeto atingisse a finalidade desejada (o desenvolvimento de toda a região), há fortes pressupostos implícitos. Além da necessidade de investimentos em capital físico, talvez o pressuposto mais importante seja a necessidade de investimentos em outras formas de capital ou até mesmo a transferência de estoques de capitais (nas formas de capitais financeiro, humano e social) de regiões mais desenvolvidas para as regiões abrangidas pelo Projeto Calha. Deve ser ressaltado ainda que a ausência de um indicador objetivamente verificável para o nível de desenvolvimento a ser alcançado leva a interpretações diferentes e, conseqüentemente, impede que se detecte o êxito ou fracasso do projeto. Esse é um problema que ocorre freqüentemente em projetos e que a estrutura lógica pretende evitar.

Quadro 3

Resumo dos principais elementos do Projeto Calha 


\begin{tabular}{|c|c|c|c|}
\hline $\begin{array}{l}\text { Resumo } \\
\text { narrativo }\end{array}$ & $\begin{array}{l}\text { Indicadores } \\
\text { objetivos }\end{array}$ & $\begin{array}{l}\text { Meios de } \\
\text { verificação }\end{array}$ & $\begin{array}{l}\text { Pressupostos } \\
\text { importantes }\end{array}$ \\
\hline \multicolumn{4}{|l|}{ Fim } \\
\hline \multicolumn{4}{|l|}{$\begin{array}{l}\text { Desenvolver toda a região } \\
\text { lindeira à hidrovia }\end{array}$} \\
\hline \multicolumn{4}{|l|}{ Propósitos } \\
\hline \multicolumn{4}{|l|}{$\begin{array}{l}\text { Modelo de gestão regional } \\
\text { elaborado que } \\
\text { operacionalize as } \\
\text { diretrizes do plano }\end{array}$} \\
\hline \multicolumn{4}{|l|}{ Produtos } \\
\hline $\begin{array}{l}\text { Diretrizes específicas } \\
\text { estabelecidas para cada } \\
\text { sub-região lindeira }\end{array}$ & $\begin{array}{l}\text { Documento com as } \\
\text { diretrizes para cada uma } \\
\text { das sub-regiões do } \\
\text { projeto }\end{array}$ & O documento & \\
\hline \multicolumn{4}{|l|}{ Insumos } \\
\hline $\begin{array}{l}\text { Utilizar as informações } \\
\text { que caracterizam as sub- } \\
\text { regiões do projeto quanto } \\
\text { às necessidades de } \\
\text { interferência para } \\
\text { direcionamento do } \\
\text { desenvolvimento }\end{array}$ & $\begin{array}{l}\text { Relatório com as } \\
\text { informa-ções sobre as } \\
\text { sub-regiões (não datado) }\end{array}$ & O relatório & \\
\hline
\end{tabular}

Depois do Projeto Calha, foi elaborado o Plano de Fomento (Cesp, 1996), já no governo Covas. Esse plano seria composto por 14 tomos específicos para cada região considerada. Como os estudos não tiveram continuidade até 2000, tais tomos não foram produzidos. Conseqüentemente, a análise deste plano limita-se ao único documento disponível, o qual possibilitou a elaboração do quadro 4. Mais uma vez, nota-se que o preenchimento possível da matriz foi apenas parcial.

\section{Quadro 4}

Resumo dos principais elementos do Plano de Fomento

\begin{tabular}{llll}
\hline $\begin{array}{l}\text { Resumo } \\
\text { narrativo }\end{array}$ & $\begin{array}{l}\text { Indicadores } \\
\text { objetivos }\end{array}$ & $\begin{array}{l}\text { Meios de } \\
\text { verificação }\end{array}$ & $\begin{array}{l}\text { Pressupostos } \\
\text { importantes }\end{array}$ \\
\hline
\end{tabular}

Fim 


\author{
Empregos e aumento da \\ arrecadação de ICMS gerados no \\ interior \\ do estado \\ Interior paulista inserido na rota \\ do Mercosul \\ Qualidade de vida melhorada \\ através da elevação do padrão \\ socioeconômico e do meio \\ ambiente \\ Propósitos \\ Desenvolvimento \\ socioeconômico fomentado em \\ mais de $8.000 \mathrm{~km}$ de áreas \\ lindeiras dos rios Tietê-Paraná \\ Investimentos privados \\ interiorizados
}

Produtos

Associações formadas para agirem em conjunto e de maneira unificada

Criação de pólos hidroindustriais, turísticos e de recebimento de insumos agrícolas ao longo da hidrovia estimulada Plano de fixação industrial elaborado Terminais hidroviários para exportação e importação para o Mercosul construídos Novos negócios, principalmente no ramo de agribusiness, criados

Insumos

Promover reuniões, envolvendo municípios lindeiros, municípios polarizadores, empresários e Cesp

${ }^{1}$ Ou será feito o transbordo por terra.

${ }^{2}$ Ou será utilizada rodovia até Piracicaba.

Verifica-se no quadro 4 que o preenchimento da matriz da estrutura lógica para o Plano de Fomento está bastante comprometido, praticamente limitando-se ao resumo do plano. O Plano de Fomento propôs a realização de reuniões envolvendo
Eclusas de Jupiá e Três Irmãos entrarão em operação O desnível de Itaipu será vencido ${ }^{1}$ O Plano de Desenvolvimento do Vale do Piracicaba será executado ${ }^{2}$ 
municípios lindeiros, municípios polarizadores, empresários e técnicos da Cesp, visando formar associações, estimular a criação de pólos, construir terminais hidroviários e criar novos negócios. Essa relação de causa e efeito entre insumos e produtos, bem como a relação entre estes e os níveis hierárquicos mais elevados do projeto estão resumidas no quadro 4 . A partir desses produtos gerados, o plano atingiria seu propósito, ou seja, o desenvolvimento de áreas lindeiras dos rios Tietê e Paraná estaria fomentado e os investimentos privados atraídos para o interior do estado. Nota-se que nenhum pressuposto foi explicitado, o que significa assumir que, uma vez promovidas as reuniões entre municípios, empresários e Cesp, com certeza, haveria êxito em atingir os propósitos do plano. Evidentemente, não pode ter sido isso o que tinham em mente os técnicos que elaboraram o plano, mas é o que se extrai dele, pois os fortes pressupostos implícitos associados aos diferentes níveis hierárquicos não foram explicitados.

Entre os pressupostos implícitos no primeiro nível hierárquico do quadro 4, está a disponibilidade de recursos, principalmente para a criação dos pólos hidroindustriais, turísticos e de recebimento de insumos agrícolas e a construção de terminais. Com relação à formação de associações para agirem em conjunto, um pressuposto importante é a disposição das lideranças locais em participar de reuniões que visassem à formação de associações. Deve ser lembrado que a relutância por parte das autoridades locais tende a ser maior ainda quando essas associações devem ser feitas com outros municípios. Nesse caso, as razões incluem as diferenças partidárias.

Vários pressupostos estão implícitos no segundo nível hierárquico do quadro 4. Por exemplo, para que os investimentos privados se direcionassem para o interior do estado, seria preciso que taxas de juros fossem compatíveis com os retornos a serem oferecidos pelos empreendimentos futuramente instalados no interior. Apesar das inúmeras críticas que as políticas governamentais de juros altos sofrem, principalmente pelos empresários, sabe-se que as taxas vigentes no país inviabilizam a realização de vários projetos de investimentos. Além disso, para que o desenvolvimento seja fomentado, políticas voltadas à educação e saúde da população provavelmente se fariam necessárias. Em outras palavras, ao buscar a formação de associações, o plano atua diretamente sobre a formação do estoque de capital social. Entretanto, embora importante, o aumento desse estoque de capital, isoladamente, não permitirá que se atinja o desenvolvimento regional. Mesmo assim, nada é indicado sobre os recursos necessários para os investimentos neste estoque de capital.

Os poucos pressupostos explícitos no Plano de Fomento estão associados ao cumprimento do seu objetivo final. Dois deles dizem respeito à viabilidade do transporte hidroviário. Um pressuposto é de que o desnível de Itaipu será vencido ou, mesmo que isso não ocorra, o transporte hidroviário continuaria viável, apesar de ser 
realizado o transbordo por terra em Itaipu. O plano não é tão incisivo com relação à viabilidade do transporte hidroviário, caso não seja executada a barragem de Santa Maria da Serra. Ela possibilitaria que a hidrovia chegasse a Piracicaba. O plano sugere que a execução do Plano de Desenvolvimento do Vale do Piracicaba, do qual a barragem faz parte, é que possibilitará o intercâmbio com o Mercosul. Quanto à aprovação para sua construção, sabe-se que, embora conste no orçamento do estado, a barragem de Santa Maria da Serra tem enfrentado entraves atribuídos a questões ambientais. Um terceiro pressuposto diz respeito à operação de Jupiá e Três Irmãos, cujas obras foram concluídas e, portanto, não seriam empecilhos ao cumprimento da finalidade do plano.

No Plano de Fomento, não são mencionados indicadores objetivos nem os meios de verificação para eles. Não seria difícil estabelecer-se alguns indicadores objetivos para esse plano. Por exemplo, quanto às atividades a serem desenvolvidas (promover reuniões), um número de reuniões periódicas em locais determinados poderia ter sido especificado, de modo que a distância percorrida pelas pessoas envolvidas no projeto, as despesas com viagens e reuniões fossem indicadores objetivamente verificáveis. Os comprovantes relativos a essas despesas bem como as atas das reuniões consistiriam nos meios de verificação para esses indicadores sugeridos. No nível hierárquico imediatamente superior (produtos), os indicadores seriam o número de associações implantadas, o número de pólos hidroindustriais, turísticos e de recebimentos de insumos agrícolas criados, o plano de fixação industrial elaborado, o número de terminais hidroviários para comercialização com o Mercosul e os novos negócios gerados. Os meios objetivamente verificáveis desses indicadores seriam as atas de abertura e de reuniões das associações e pólos gerados, o documento elaborado (o plano) e os alvarás concedidos para instalação e funcionamento de indústrias e empresas na região abrangida pelo plano.

Nos níveis mais elevados do Plano de Fomento, os indicadores objetivamente verificáveis também não foram explicitados. Poderiam ser utilizados indicadores divulgados por instituições de pesquisa relacionados a desenvolvimento humano, condição de vida ou, ainda, construção civil, ou até mesmo elaborado um indicador específico para a região. Para o nível mais elevado do plano (fim), a variação percentual no ICMS, no número de empregos e nas estatísticas sobre transporte no interior de São Paulo para o Mercosul consistiriam em indicadores objetivamente verificáveis. Também seria necessário optar-se por algum índice de qualidade de vida para completar os indicadores para este último nível. À exceção deste último indicador, que, uma vez determinado, poderia ser calculado periodicamente ou utilizar-se de algum indicador já disponível nas instituições de pesquisa, os outros poderiam ser verifi-cados com informações obtidas nas contas do estado.

Por se referir a uma região diferente daquela do Projeto Calha, o Plano de Fomento não pode beneficiar-se de suas informações. Do ponto de vista técnico, a 
diferença na utilização das regiões gera dificuldades em aproveitamento dos dados, que, uma vez obtidos para o Calha, poderiam ser úteis na elaboração e execução do Plano de Fomento. Essa falta de continuidade detectada não foi uma particularidade desses dois projetos mencionados, mas, sim, uma regra observada na atuação governamental no que diz respeito aos planos de desenvolvimento associados aos vales do Tietê e do Paraná.

Pode-se dizer que os planos de desenvolvimento encontrados para a região dos vales do Tietê e do Paraná não preenchem as exigências mínimas que deveriam constar em projetos bem elaborados. Neste artigo, considera-se bem elaborado um projeto que apresente elementos suficientes para o preenchimento da matriz usada no método da estrutura lógica. O Master Plan (ADTP, 1996), única iniciativa do setor privado, não permitiu sequer o encadeamento lógico de causa e efeito das ações e resultados do projeto. Os projetos Calha e Fomento deixam lacunas ao não explicar os pressupostos e não deixam que se detectem as responsabilidades pelas falhas. Além disso, a ausência de indicadores objetivamente verificáveis impede que se verifique se os objetivos dos diferentes níveis foram alcançados. É importante lembrar que, se esses indicadores e pressupostos tivessem sido devidamente especificados, mesmo quando não se alcançassem os objetivos aos quais os planos se propunham, seria possível detectarem-se as responsabilidades sobre a frustração das expectativas.

Os estudos voltados a municípios específicos dos vales dos rios Tietê e Paraná são de diferentes períodos da história recente. Na fase de construção das obras, os projetos tratavam de municípios localizados mais próximos a elas. São dessa época estudos sobre Ilha Solteira, Avanhandava, Teodoro Sampaio e Rosana. Com a hidrovia, municípios mais próximos dos centros consumidores (Pederneiras e Piracicaba) parecem ter despertado maior interesse, embora o número de projetos a ser analisado ainda seja pequeno. Os projetos encontrados para os municípios foram para Ibitinga, Rosana, Penápolis, Rubinéia, Santa Fé do Sul, Três Fronteiras, Buritama, Lourdes, Turiuba e Zacarias. O plano para o município de Penápolis foi o único que mencionou, embora bastante resumidamente, possibilidades de irrigação (Cesp, 1997).

Os projetos analisados para os municípios seguiram sempre um mesmo padrão e enfatizam a construção de obras nos municípios lindeiros. Essa padronização permite que, para não se estender demasiadamente a apresentação dos resultados, a discussão se limite ao detalhamento de um dos planos. Serão apresentados os resultados da análise de somente um projeto, que abrange três municípios. Mais uma vez, utilizou-se o método da estrutura lógica. Ainda visando sintetizar a discussão, será omitida a extensa matriz de estrutura lógica obtida para o referido plano. Deve ser ressaltado que, embora extenso pelo grande número de insumos e produtos existentes, o projeto ficou muito aquém das exigências mínimas indicadas pelo método. 
A Cesp elaborou planos para alguns dos 17 pólos potenciais, para novas opções de investimento que estabeleceu ao longo da hidrovia. Entre esses planos, encontra-se um para os municípios de Rubinéia, Santa Fé do Sul e Três Fronteiras, que formam um único pólo. Os municípios de Buritama, Lourdes, Turiuba e Zacarias, para os quais também foi elaborado um plano, não foram incluídos entre os 17 pólos mencionados, mas fazem parte do Núcleo de Turismo do Sol. ${ }^{1}$ Os municípios de Buritama, Turiuba e Zacarias comunicam-se com o reservatório de Nova Avanhandava, e Lourdes e também Buritama são lindeiros a Três Irmãos.

O plano da Cesp insiste na necessidade de engajamento efetivo dos municípios do pólo turístico formado por Rubinéia, Santa Fé do Sul e Três Fronteiras, no Programa Nacional de Municipalização do Turismo (PNMT - Cesp, 1995a). Entretanto, o texto não esclarece o que seria necessário para que tal engajamento ocorresse e, ao apresentar o prognóstico para Rubinéia, deixa a impressão de que os planos Diretor e Turístico, o cadastramento dos municípios no Roteiro de Informações Básicas para Identificação de Municípios Prioritários para o Desenvolvimento do Turismo pela Embratur (Rimtur) e até mesmo o Conselho e o Fundo Municipal de Turismo seriam necessários para tal engajamento, conforme se observa no trecho que se refere ao PNMT. A participação "efetiva" nesse programa foi considerada imprescindível. "Assim, faz-se necessário a elaboração de um Plano Diretor e de um Plano de Desenvolvimento Turístico. [O município] já consta do Rimtur, e possui o Conselho e o Fundo Municipal de Turismo” (Cesp, 1995a:29).

Diante do texto do Plano de Fomento Turístico para Rubinéia, Santa Fé do Sul e Três Fronteiras, entendeu-se que os planos Diretor e Turístico seriam insumos, e o engajamento efetivo no PNMT, um produto. De qualquer modo, o termo "efetivo" dá margem a diversas interpretações, inclusive de que "algo" deve ser feito para que o engajamento ocorra e que não se trata apenas de uma simples inscrição no programa. Há ainda outra observação necessária, referente à exigência de cadastro no Rimtur e formação de Conselho Municipal de Turismo para obtenção de recursos da Financiadora de Estudos e Projetos (Finep) para elaborar os planos. Interpretando sob esse prisma, os planos poderiam ser vistos como produtos e o cadastramento no Rimtur e a formação do conselho, como insumos. Entretanto, uma vez que os três municípios já têm cadastro no Rimtur e os conselhos municipais já estão formados em Rubinéia e Santa Fé do Sul e, na época em que foi elaborado o Plano de Fomento, o conselho municipal já estava em fase de criação em Três Fronteiras, pode-se partir da elaboração dos planos como insumo sem entrar no mérito de como os re-

\footnotetext{
${ }^{1}$ Os núcleos de turismo foram definidos pela Secretaria de Esportes e Turismo do Estado de São Paulo, em 1993 (Cesp, 1995a).
} 
cursos para elaborá-los serão obtidos. Essa foi a base da seqüência lógica utilizada para elaborar a matriz de estrutura lógica para o plano dos três municípios em questão. Cabe ressaltar que fica reconhecida a fragilidade do Plano de Fomento Turístico, pois até mesmo para a elaboração dos planos Diretor e Turístico há dependência da existência de recursos.

A elaboração dos planos Diretor e Turístico para os municípios de Rubinéia, Três Fronteiras e Santa Fé do Sul contribuiria, juntamente com as sugestões e o prognóstico apresentados no Plano de Fomento Turístico, para que a região fosse auxiliada na formação do pólo turístico e as municipalidades fossem devidamente assessoradas em direção ao desenvolvimento. Esta relação é parte do encadeamento lógico entre o nível hierárquico mais baixo (insumos) e o nível imediatamente superior (produtos). Quanto aos outros insumos considerados, chama a atenção a construção de marinas e terminal hidroviário para passageiros. Não são atividades tão simples de serem realizadas pois carecem de projetos, e isso não foi lembrado de modo específico. Na realidade, o texto ressaltou a necessidade de outros estudos e considerou as proposições/recomendações apresentadas no plano apenas em caráter preliminar. Pressupôs-se, portanto, no nível hierárquico mais baixo, que outros estudos seriam realizados, e os produtos (as obras construídas) efetivamente existiriam. Os recursos para tais obras, entretanto, não foram devidamente tratados no plano, que se limitou a mencionar vagamente as possibilidades de obtenção de recursos.

Uma vez obtidos os produtos do Plano de Fomento Turístico para os municípios de Rubinéia, Santa Fé do Sul e Três Fronteiras, é preciso verificar se os propósitos seriam atingidos. Nesse ponto, nota-se que os pressupostos existentes são muito fortes e comprometem o alcance dos propósitos. São pressupostos associados à hidrovia e alguns deles à rota do Mercosul. Dados as constantes dificuldades econômicas pelas quais passam os países do Mercosul e o conseqüente enfraquecimento do acordo, esses pressupostos podem não se cumprir, e o desenvolvimento do turismo ao longo da hidrovia ser comprometido, ainda que apenas no curto prazo. Especificamente quanto ao pressuposto relacionado a incentivos que os empresários teriam, além das dificuldades associadas à rota Mercosul, há ainda o risco em relação à própria hidrovia. Embora as possibilidades de fechamento do canal construído em Pereira Barreto para ligar os rios Tietê e Paraná pareçam remotas, isso foi considerado, durante o período que antecedeu ao recente racionamento de energia, para elevar os níveis de água dos reservatórios. Evidentemente, o próprio risco já é um desestímulo a mais para os empresários, em geral desmotivados, principalmente pelas taxas de juros vigentes no país. Com o comprometimento do alcance dos propósitos do plano, está conseqüentemente comprometido o cumprimento do objetivo final. Esse comprometimento é maior ainda ao se constatar que os pressupostos existentes para o alcance do fim do Plano de Fomento Turístico (o desenvolvimento das comunidades lindeiras à hidrovia e melhoria da qualidade de vida) também es- 
tão relacionados ao retorno de investimentos realizados, ou a serem realizados, em empreendimentos ao longo da hidrovia.

O que mais chama a atenção no plano para Rubinéia, Santa Fé do Sul e Três Fronteiras é a ausência total de indicadores objetivos e seus respectivos meios de verificação. Isso fez com que na matriz de estrutura lógica, obtida a partir do projeto, as duas colunas intermediárias ficassem em branco. Assim, como nos planos discutidos anteriormente, são válidas as observações quanto à impossibilidade de se avaliar objetivamente o êxito ou fracasso das etapas do plano. Como ilustração, alguns indicadores objetivos para os insumos que consistam em obras a serem construídas ou melhorias na infra-estrutura poderiam ser relativamente simples de serem elaborados, considerando-se indicadores da construção civil e estabelecendo-se um prazo para atingi-los. Esse tipo de indicador poderia ser verificável por informações a serem obtidas nas prefeituras municipais, como, por exemplo, alvarás para construção, despesas com obras de saneamento, instalações elétricas e outras. Indicadores do mesmo tipo poderiam ser utilizados para os produtos associados a esses insumos. O engajamento efetivo no PNMT dentro de um prazo definido poderia completar os indicadores objetivamente verificáveis para os produtos e a documentação referente (atas, lista de presenças constando a participação de representantes municipais etc.) seriam os meios de verificação do engajamento efetivo no PNMT dentro de determinado prazo.

A mesma ausência de indicadores objetivos e seus meios de verificação detectada no plano para Rubinéia, Santa Fé do Sul e Três Fronteiras é observada no Plano de Fomento Turístico para os municípios de Buritama, Lourdes, Turiuba e Zacarias (Cesp, 1998). Assim, além de mostrar elementos do encadeamento lógico encontrado e apresentado no resumo narrativo e dos pressupostos importantes, deve ser salientado que as sugestões apresentadas para o plano anterior também são válidas. Apesar da semelhança entre os dois planos, detectaram-se algumas diferenças sutis que serão destacadas.

O Plano de Fomento para os municípios de Buritama, Lourdes, Turiuba e Zacarias apresenta como insumos idéias sobre alternativas de turismo que, uma vez compreendidas, gerarão planos diretores, de turismo e de marketing, além de auxiliarem a municipalidade a encontrar formas de desenvolvimento. São idéias gerais, informando sobre possibilidades de aproveitamento dos rios e lagos, e a grande maioria encontrase em todos os planos analisados. Segundo o plano, tais idéias deverão colaborar para a elaboração de outros planos. É interessante notar que essa é uma diferença no caminho lógico seguido nesse plano em relação ao anterior, no qual os planos diretores e de turismo foram entendidos como insumos. O resultado dessa interpretação foi uma seqüência lógica na qual um insumo bastante importante do Plano de Fomento Turístico para os municípios de Buritama, Lourdes, Turiuba e Zacarias é o engajamento dos municípios no PNMT que, juntamente com as idéias apresentadas e com a estruturação técnica dos municípios (que se beneficiariam também do engajamento no PNMT), 
gerariam os planos diretores, turístico e de marketing, bem como recursos humanos capacitados. Deve ser lembrado que o plano reconhece a necessidade de mais informações sobre as idéias apresentadas.

A idéia de planejar um grupo de municípios, visando à formação de um pólo, é uma evolução em relação a outros planos nos quais se enfocou apenas um município, como nos planos para o município de Rosana (Cesp, 1993) e Ibitinga (Cesp, 1995b). Para este último, dada a particularidade de possuir uma indústria de bordado reconhecida nacionalmente, um plano individual é justificável. O município de Rosana, isoladamente, corresponde a um dos pólos potenciais de investimento ao longo da hidrovia e mereceu, assim como Ibitinga, um plano específico. Por terem sido elaborados exatamente nos mesmos moldes que os dois últimos planos analisados, a discussão sobre as matrizes para os planos de Rosana e Ibitinga seria repetitiva. Ressalta-se, porém que, em linhas gerais, as críticas e sugestões apresentadas para o projeto de Rubinéia, Santa Fé do Sul e Três Fronteiras são perfeitamente válidas para os projetos para Rosana e Ibitinga.

\section{Conclusão}

As alternativas propostas para os municípios dos vales dos rios Tietê e Paraná, que constam nos projetos e planos analisados, são incompletas e inconsistentes, como se detectou pelo método da estrutura lógica. Chama a atenção, por exemplo, o fato de as alternativas propostas para o desenvolvimento da região serem fortemente vinculadas à hidrovia Tietê-Paraná e terem fortes pressupostos relacionados ao seu sucesso. A grande maioria desses pressupostos, entretanto, não está explicitada nos planos e projetos. Acrescenta-se a essa constatação a falta de propostas para o desenvolvimento que estejam em conformidade com a teoria do desenvolvimento. Os projetos enfatizaram investimentos em capital físico e desconsideram as outras formas de capital e suas relações com o desenvolvimento.

\section{Referências bibliográficas}

ADTP (AGÊNCIA DE DESENVOLVIMENTO TIETÊ-PARANÁ). Tietê-Paraná Master Plan: infra-estrutura, mercado \& negócios. São Paulo: ADTP, 1996.

CESP (COMPANHIA ENERGÉTICA DE SÃO PAULO). Município de Rosana: macroplano turístico e industrial. São Paulo: Cesp, 1993. (Série Pesquisa e Desenvolvimento, 90).

Plano de fomento turístico: Rubinéia, Santa Fé do Sul e Três Fronteiras. São Paulo: Cesp, 1995a. (Série Pesquisa e Desenvolvimento, 134).

Estância turística de Ibitinga: macroplano de desenvolvimento turístico de Ibitinga. São Paulo: Cesp, 1995b. (Série Pesquisa e Desenvolvimento, 106). 
—. Hidrovia Tietê-Paraná: plano de fomento. São Paulo: Cesp, 1996. (Série Pesquisa e Desenvolvimento, 133).

—. Plano de desenvolvimento e integração hidroviário de Penápolis. São Paulo: Cesp, 1997. (Série Pesquisa e Desenvolvimento, 142).

Plano de fomento turístico: Buritama, Lourdes, Turiuba e Zacarias. São Paulo: Cesp, 1998. (Série Pesquisa e Desenvolvimento, 144).

CITP (CONSÓRCIO INTERMUNICIPAL TIETÊ-PARANÁ). Tietê-Paraná: Projeto Calha caracterização da área do projeto. São Paulo: CITP, 1994.

JACKSON, Bill. Designing projects and project evaluation using the logical framework approach. Gland: IUCN, 1998. Disponível em: <www.iucn.org/themes/eval/english/1fa.htm>. Acesso em: 18 jun. 2001.

MANAGEMENT SYSTEMS INTERNATIONAL. Estrutura lógica: um guia para gerentes para planejar e avaliar projetos de forma científica. Trad. de Francisco B. Tancredi. s.n.t.

NORAD (NORWEGIAN AGENCY FOR DEVELOPMENT CO-OPERATION). The logical framework approach (LFA): handbook for objectives-oriented planning. 4. ed. Oslo: Norad, 1999. 